in vivo $34: 889-896(2020)$

doi:10.21873/invivo.11854

\title{
Recurrence of Atrial Fibrillation in Dependence of Left Atrial Volume Index
}

\author{
MALTE KRANERT ${ }^{1,2}$, TETYANA SHCHETYNSKA-MARINOVA ${ }^{1}$, VOLKER LIEBE $^{1,2}$, CHRISTINA DOESCH $^{1}$, \\ THEANO PAPAVASSILIU ${ }^{1,2}$, IBRAHIM AKIN ${ }^{1,2}$, MARTIN BORGGREFE $^{1,2}$ and ANNA HOHNECK HOH $^{1,2}$ \\ ${ }^{1}$ First Department of Medicine - Cardiology, University Medical Centre Mannheim, \\ Medical Faculty Mannheim, University of Heidelberg, Mannheim, Germany; \\ ${ }^{2}$ DZHK (German Centre for Cardiovascular Research), University Medical Centre Mannheim, \\ Medical Faculty Mannheim, University of Heidelberg, Mannheim, Germany
}

\begin{abstract}
Background/Aim: Despite advances in the treatment strategies of patients with atrial fibrillation $(A F)$, the risk of $A F$ recurrences is still over 50\%. An increased left atrial volume index (LAVI) reflects left ventricular diastolic dysfunction $(D D)$ and deterioration of the LA function. This study aims to determine $A F$ recurrence following cardioversion $(C V)$ or catheter ablation for AF (pulmonary vein isolation; $P V I)$ in dependence of DD and LAVI. Patients and Methods. One hundred and sixty-two patients with paroxysmal or persistent $A F$ in whom either $C V$ or PVI were performed were

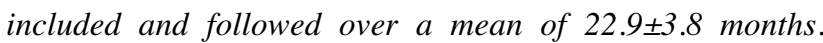
Recurrence was defined as any recurrence of AF that occurred 3 months following the procedure. DD and LAVI were assessed using transthoracic echocardiography (TTE). Results: Recurrent AF occurred in 100 (61.7\%) patients, predominantly following CV [CV 41 (76.2\%) vs. PVI 59 (54.6\%), $p<0.0001]$. Both DD and an increased LAVI were more common in the recurrence-group [DD $46.0 \%$ vs. $14.5 \%, p=0.0001$; LAVI $\left.\left(\mathrm{ml} / \mathrm{m}^{2}\right) 49.0 \pm 18.6 \mathrm{vs} .26 .3 \pm 7.0, p<0.0001\right]$. ROC analysis revealed $L A V I>36 \mathrm{ml} / \mathrm{m}^{2}$ as cut-off ( $p<0.0001, A U C=0.92$, $95 \% C I=0.87-0.97$, sensitivity $=76 \%$, specificity $=94 \%)$. In the multivariate analysis, $D D(H R=1.6,95 \% C I=1.3-2.1, p=0.04)$ and LA enlargement (defined as $L A V I>36 \mathrm{ml} / \mathrm{m}^{2}$ with $H R=2.1$, $95 \% C I=1.8-2.7, p<0.0001)$ could be identified as independent predictors of $A F$ recurrence after attempting to control the heart rhythm. Conclusion: LA enlargement and DD are
\end{abstract}

This article is freely accessible online.

Correspondence to: Anna Hohneck, First Department of Medicine - Cardiology, University Medical Centre Mannheim, TheodorKutzer-Ufer 1-3, 68167 Mannheim, Germany. Tel: +49 6213832204, Fax: +496213832172, e-mail: annalena.hohneck@umm.de

Key Words: Atrial fibrillation, cardioversion, catheter ablation, diastolic dysfunction, LAVI, recurrence. independent risk factors associated with AF recurrence after initial successful rhythm control attempt. These findings have implications for timing of either ablation or $C V$.

Atrial fibrillation (AF) is a progressive condition with a major impact on morbidity, mortality and quality of life (QoL) (1-3). Atrial remodeling is recognized as a key feature in the development and maintenance of AF (4). In addition to the increased mortality risk, patients suffering from AF are at stake for developing congestive heart failure (HF) (5). Even in patients with preserved left ventricular ejection fraction (LVEF), AF has been associated with $\mathrm{LV}$ diastolic dysfunction (6). The left atrium (LA) is directly exposed to elevated LV filling pressures during diastole. This chronic sustained elevation results in the remodeling and stiffening of the LA and can be reflected in its enlargement and in elevated blood volume.

Nevertheless, AF is not always perceived as a serious health threat. Due to recent studies there is now a paradigm shift for treating AF in patients with $\mathrm{HF}$ with catheter ablation to improve mortality rates (7).

At present, hypertension and LA diameter are independent pre-procedural predictors of AF recurrence (8). Moreover, the more time the cardiac rhythm remains in $\mathrm{AF}$, the higher is the recurrence rate due to fibrotic remodeling processes (9-11).

We performed this study to determine the recurrence for AF following cardioversion (CV) or catheter ablation for AF (pulmonary vein isolation; PVI) with respect to diastolic dysfunction and the left atrial volume index (LAVI) and to detect a cut-off for a better risk stratification.

\section{Patients and Methods}

Study population. 162 consecutive patients with $\mathrm{AF}$ who underwent CV or PVI in the $1^{\text {st }}$ Medical Department (Cardiology), University Medical Centre Mannheim were enrolled. Recruitment started in 


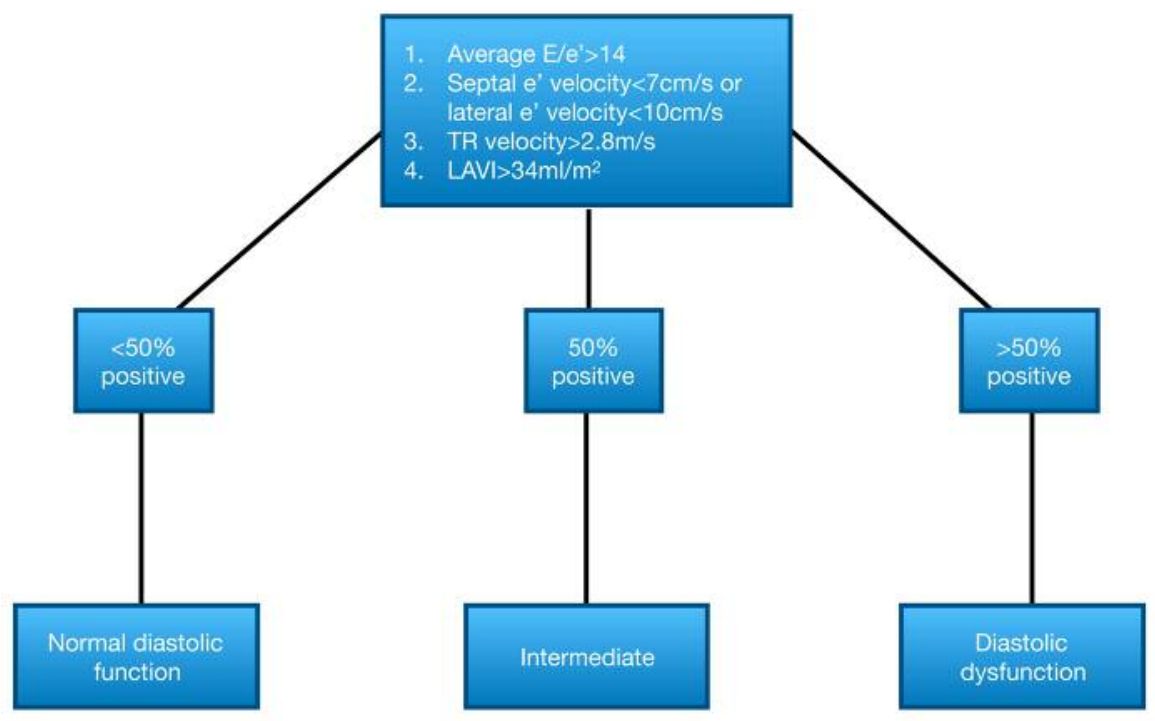

Figure 1. Algorithm for diagnosis of LV diastolic dysfunction according to Nagueh et al (22). LAVI: Left atrial volume index; LV: left ventricular; TR: tricuspid regurgitation.

February 2017 and ended in May 2017. Patients were then followed over a mean time of $22.9 \pm 3.8$ months. The presence of AF was based on electrocardiographic evidence, including Holter monitoring and classification of AF was performed in accordance to the current guidelines of the European Society of Cardiology (ESC) for the management of atrial fibrillation (12), whereby two patterns, paroxysmal and permanent $\mathrm{AF}$, were differentiated.

Inclusion criteria were: i) atrial fibrillation, ii) pattern- and sexindependent, iii) age $>18$ years and iv) given written informed consent. Exclusion criteria at the time of inclusion were: i) acute myocardial infarction, ii) cardiogenic shock, iii) indication for aortocoronary bypass operation, iv) acute stroke, v) minimal heart rate at rest below $50 \mathrm{bpm}$, vi) aortic aneurysm or dissection, vii) hypotension with blood pressure $<90 / 50 \mathrm{mmHg}$ or hypertension with systolic blood pressure $>160 \mathrm{mmHg}$ and viii) need for constant pacemaker-stimulation.

The study design complies with the declaration of Helsinki (13) and was approved by local the ethical committee, Medical Ethic Commission II, at the Faculty of Medicine Mannheim, University of Heidelberg, Germany. Written informed consent was obtained from all patients and data were analyzed anonymously. Data protection was in accordance to the EU Data Protection Directive.

Echocardiographic and Doppler studies. Transthoracic echocardiography (TTE) was performed in supine/left lateral decubitus position with a phased-array ultrasound sector scanner (Vivid E9, GE Healthcare, UK) and a $3.5 \mathrm{MHz}$ transducer. Twodimensional images were obtained in the standard parasternal and apical views. Left ventricular (LV) volume and ejection fraction (EF) were performed using the biplane Simpson's method (14). All Doppler recordings were obtained with a sweep speed of $100 \mathrm{~mm} / \mathrm{s}$.

Left atrium. LA dimensions were measured at end-systole and the LA volume was calculated using the biplane area-length method $(15,16)$. The anteroposterior diameter of the LA was measured by
M-Mode in the parasternal long axis view, perpendicular to the long axis of the aortic root and measured at the level of the aortic sinus by using the leading-edge to leading-edge method (17). Additionally, areas of the LA were obtained in apical 4 and 2 chamber views (A1 and A2, respectively) by tracing the endocardial border, and the long axis (L) was measured as the minimum length from the plane of the mitral annular plane to the roof of the LA.

LA volume was calculated using the following formula:

$$
L A \text { volume }=0.85 \times \mathrm{A} 1 \times \mathrm{A} 2 \mathrm{~L}
$$

LAVI was obtained by indexing the LA volume to the body surface area (BSA), reported as milliliters per square meter $\left(\mathrm{ml} / \mathrm{m}^{2}\right)$. BSA was calculated using the Mosteller method after recording weight and height.

Diastolic function. Left ventricular diastolic filling was determined by Doppler-derived measurements $(18,19)$. Mitral inflow velocity was assessed using Doppler echocardiography from apical 4 chamber view, keeping the sample volume at the tips of the mitral leaflets. In addition, the mitral annulus velocities were measured using Tissue Doppler Imaging (TDI) (20) (Vivid E9, GE Healthcare, UK), at both sides (septal and lateral mitral annulus) to determine the ratio of E/e'. Due to the variable cycle length in patients with atrial fibrillation, measurements were averaged over 5 cardiac cycles (21). Diastolic function was categorized into: i) normal, ii) indeterminate and iii) dysfunctional, according to the current algorithms of the American Society of Echocardiography (22) (displayed in Figure 1).

Statistical analysis. All data are presented as a mean \pm standard deviation. Continuous parameters were compared using a 2-tailed student's $t$-test. Receiver operating characteristic (ROC) curves were used in the whole group of patients to find the optimal cut-off values for LAVI and LA diameter (measured by M-Mode), 
Table I. Patient demographics, baseline characteristics and concomitant medication. Data are presented as mean $\pm S D$ or $n(\%)$ of subjects.

\begin{tabular}{|c|c|c|c|c|}
\hline & $\begin{array}{l}\text { All patients } \\
\text { with AF } \\
(n=162)\end{array}$ & $\begin{array}{l}\text { Non- } \\
\text { recurrence } \\
(\mathrm{n}=62)\end{array}$ & $\begin{array}{l}\text { Recurrence } \\
\quad(\mathrm{n}=100)\end{array}$ & $p$-Value \\
\hline Age (years) & $70.8 \pm 1.8$ & $69.0 \pm 11.4$ & $71.7 \pm 8.7$ & 0.08 \\
\hline Gender $(\mathrm{m} / \mathrm{f})$ & $116 / 58$ & $44 / 18$ & $60 / 40$ & 0.16 \\
\hline BMI $\left(\mathrm{kg} / \mathrm{m}^{2}\right)$ & $28.1 \pm 1.2$ & $27.4 \pm 5.2$ & $29.1 \pm 6.3$ & 0.07 \\
\hline \multicolumn{5}{|l|}{$\begin{array}{l}\text { Cardiovascular } \\
\text { parameters }\end{array}$} \\
\hline Heart rate (bpm) & $69.8 \pm 9.9$ & $69.1 \pm 12.6$ & $70.2 \pm 15.0$ & 0.63 \\
\hline $\mathrm{SBP}(\mathrm{mmHg})$ & $128.8 \pm 21.2$ & $127.5 \pm 15.3$ & $129.6 \pm 17.1$ & 0.43 \\
\hline $\mathrm{DBP}(\mathrm{mmHg})$ & $76.3 \pm 9.2$ & $75.4 \pm 9.5$ & $76.8 \pm 9.2$ & 0.35 \\
\hline \multicolumn{5}{|l|}{ Concomitant diseases } \\
\hline Hypertension, n (\%) & $125(82.2)$ & $41(66.1)$ & $84(84.0)$ & $<0.01$ \\
\hline Diabetes, n (\%) & $20(12.4)$ & $5(8.0)$ & $15(15.0)$ & 0.19 \\
\hline $\begin{array}{l}\text { Current smoker, } \\
\mathrm{n}(\%)\end{array}$ & $17(10.5)$ & $5(8.1)$ & $12(12.0)$ & 0.50 \\
\hline $\begin{array}{l}\text { NYHA III/IV, } \\
\mathrm{n}(\%)\end{array}$ & $47(29.0)$ & $7(11.3)$ & $40(40.0)$ & $<0.001$ \\
\hline $\begin{array}{l}\text { GFR }<60 \\
\left(\mathrm{ml} / \mathrm{min} / 1.73 \mathrm{~m}^{2}\right) \\
\mathrm{n}(\%)\end{array}$ & $49(30.3)$ & $12(19.4)$ & $37(37.0)$ & 0.02 \\
\hline Creatinine (mg/dl) & $1.1 \pm 0.2$ & $1.0 \pm 0.2$ & $1.3 \pm 0.6$ & 0.02 \\
\hline $\begin{array}{l}\text { Current GFR } \\
\text { (MDRD-formula) } \\
\left(\mathrm{ml} / \mathrm{min} / 1.73 \mathrm{~m}^{2}\right)\end{array}$ & $66.0 \pm 25.3$ & $72.3 \pm 17.4$ & $62.0 \pm 19.1$ & $<0.01$ \\
\hline Prior stroke/TIA & $16(9.9)$ & $4(6.5)$ & $11(11.0)$ & 0.34 \\
\hline $\mathrm{CAD}, \mathrm{n}(\%)$ & $48(29.6)$ & $15(24.2)$ & $33(33.0)$ & 0.24 \\
\hline 3-vessel disease & $14(28.0)$ & $4(8.0)$ & $10(10.0)$ & 0.44 \\
\hline Heart failure, n (\%) & $68(42.0)$ & $12(19.4)$ & $56(56.0)$ & $<0.0001$ \\
\hline HFrEF, n (\%) & $15(9.3)$ & $1(1.6)$ & $14(14.0)$ & $<0.01$ \\
\hline HFpEF, n (\%) & $49(30.3)$ & $10(16.1)$ & $39(39.0)$ & $<0.001$ \\
\hline$\geq$ Moderate MI, n (\%) & $23(14.2)$ & $5(8.1)$ & $18(36.0)$ & 0.08 \\
\hline$\geq$ Moderate MS, n (\%) & $6(3.7)$ & $5(5.0)$ & $1(1.6)$ & 0.28 \\
\hline \multicolumn{5}{|c|}{ Anticoagulant therapy } \\
\hline VKA, n (\%) & $12(7.4)$ & $4(6.5)$ & $8(8.0)$ & 0.72 \\
\hline Dabigatran, n (\%) & $31(19.1)$ & $8(12.9)$ & $24(24.0)$ & 0.09 \\
\hline Apixaban, n (\%) & $43(26.5)$ & $16(25.8)$ & $26(26.0)$ & 0.98 \\
\hline Rivaroxaban, n (\%) & $42(25.9)$ & $11(17.7)$ & $31(31.0)$ & 0.06 \\
\hline \multicolumn{5}{|l|}{ Concomitant } \\
\hline \multicolumn{5}{|l|}{ Medication, n (\%) } \\
\hline$\beta$-Blocker & $118(72.8)$ & $41(66.1)$ & 77 (77.0) & 0.13 \\
\hline $\begin{array}{l}\text { Calcium channel } \\
\text { blocker }\end{array}$ & $28(17.3)$ & $9(14.5)$ & $19(19.0)$ & 0.47 \\
\hline ACE-inhibitor/ARB & 87 (53.7) & $32(51.6)$ & $55(55.0)$ & 0.68 \\
\hline Amiodarone & $5(3.1)$ & $4(6.5)$ & $11(11.0)$ & 0.14 \\
\hline $\begin{array}{l}\text { Other antiarrhythmic } \\
\text { agent }\end{array}$ & $13(8.0)$ & $2(3.2)$ & $11(11.0)$ & 0.08 \\
\hline Digitalis & $15(9.3)$ & $1(1.6)$ & $14(14.0)$ & $<0.01$ \\
\hline Statine & $72(44.4)$ & $24(38.7)$ & $48(48.0)$ & 0.23 \\
\hline $\begin{array}{l}\text { Oral diabetes } \\
\text { medication }\end{array}$ & $10(6.2)$ & $3(4.8)$ & $7(7.0)$ & 0.58 \\
\hline Insulin & $6(3.7)$ & $2(3.2)$ & $3(3.0)$ & 0.94 \\
\hline
\end{tabular}

ACE: Angiotensin converting enzyme; ARB: aldosterone receptor blocker; BMI: body mass index; CAD: coronary artery disease; DBP: diastolic blood pressure; HfpEF: heart failure with preserved ejection fraction; HfrEF: heart failure with reduced ejection fraction; GFR: glomerular filtration rate; MI: mitral insufficiency; MS: mitral stenosis; NYHA: New York Heart Association; SBP: systolic blood pressure; TIA: transitoric ischemic attack; VKA: vitamin $\mathrm{K}$ antagonist.
Table II. Atrial fibrilation characteristics recurrence vs. non-recurrence data are presented as mean $\pm S D$ or $n(\%)$ of subjects.

\begin{tabular}{lcccc}
\hline & $\begin{array}{c}\text { All patients } \\
\text { with AF } \\
(\mathrm{n}=162)\end{array}$ & $\begin{array}{c}\text { Non- } \\
\text { recurrence } \\
(\mathrm{n}=62)\end{array}$ & $\begin{array}{c}\text { Recurrence } \\
(\mathrm{n}=100)\end{array}$ & $p$-Value \\
\hline Atrial fibrillation & & & & \\
$\quad$ Permanent, n (\%) & $62(38.3)$ & $17(27.4)$ & $45(45.0)$ & 0.03 \\
Intervention (PVI/CV) & $108 / 54$ & $46 / 15$ & $62 / 39$ & 0.07 \\
Duration date of & $66.9 \pm 81.3$ & $70.0 \pm 88.6$ & $65.8 \pm 77.5$ & 0.75 \\
index episode until & & & & \\
intervention (months) & & & & \\
CHA 2 DS -Vasc-Score $^{-}$ & $2.9 \pm 0.7$ & $2.5 \pm 1.6$ & $3.3 \pm 1.6$ & $<0.01$ \\
HASBLED-Score & $2.1 \pm 1.1$ & $1.7 \pm 1.1$ & $2.3 \pm 1.0$ & $<0.001$ \\
EHRA & $2.3 \pm 2.1$ & $2.1 \pm 0.8$ & $2.4 \pm 0.9$ & 0.02 \\
$\quad$ I, n (\%) & $33(20.4)$ & $17(27.4)$ & $16(16.0)$ & 0.08 \\
II, n (\%) & $50(30.9)$ & $25(40.3)$ & $25(25.0)$ & 0.04 \\
III, n (\%) & $72(44.4)$ & $19(30.6)$ & $53(53.0)$ & $<0.01$ \\
IV, n (\%) & $6(3.7)$ & $1(1.6)$ & $4(4.0)$ & 0.40 \\
Symptomatic & $75(46.3)$ & $18(29.0)$ & $56(57.0)$ & $<0.001$ \\
(EHRA $\geq I I I), n(\%)$ & & & & \\
Prior cardioversion & $74(45.7)$ & $18(29.0)$ & $56(56.0)$ & $<0.001$ \\
Prior PVI & $39(24.1)$ & $8(12.9)$ & $31(31.0)$ & $<0.01$ \\
History of AFlut & $47(29.0)$ & $12(19.4)$ & $35(35.0)$ & 0.03 \\
\hline
\end{tabular}

Aflut: Atrial flutter; CV: cardioversion; EHRA: European Heart Rhythm Association; PVI: pulmonary vein isolation.

maximizing the sum of sensitivity and specificity with help of the Youden-Index. Multivariate analysis was performed with logistic regression analysis using block entry of the following variables: i) diastolic dysfunction and ii) LA enlargement (defined as LAVI $>36$ $\mathrm{ml} / \mathrm{m}^{2}$ ), provided to have a $p<0.01$ in the univariate analysis.

All results were considered statistically significant when $p<0.05$. Analyses were performed using the Statistical 1 Package for Social Sciences (SPSS for Windows 14.0, Chicago, IL, USA) and the GraphPad Prism 7.0 (Graphpad Software, Inc., CA, USA) software.

\section{Results}

Patient baseline characteristics. A total of 162 consecutive patients were followed for a mean time of $22.9 \pm 3.8$ months. AF recurred in 61.7\% (100 patients). Baseline clinical characteristics are shown in Table I.

There were no significant differences between the recurrence group and the non-recurrence group regarding i) sex (male $60 v s .44$, female $40 v s .18, p=0.20$ ), ii) BMI (27.4 $\left.\mathrm{kg} / \mathrm{m}^{2} v s .29 .1 \mathrm{~kg} / \mathrm{m}^{2}, p=0.07\right)$, or iii) diabetes [15 (15\%) vs. $5(8.0 \%), p=0.19]$, iv) hypertension [84 (84\%) vs. $41(66.1 \%)$, $p<0.01]$. However, heart failure [56 (56\%) vs. $12(19.4 \%)$, $p<0.0001]$ occurred significantly more often in the recurrencegroup compared to the non-recurrence group. In further detail, heart failure with preserved ejection fraction (HFpEF) [39 (39\%) vs. 10 (16.1\%), $p<0.001]$ showed way more significant difference than did heart failure with reduced ejection fraction (HFrEF) [14 (14\%) vs. 1 (1.6\%), $p<0.01]$. Significant 
impairment due to heart failure symptoms [40 (40\%) vs. 7 $(11.3 \%), p<0.001]$, reflected in New York Heart Association (NYHA) score III/IV, could be observed more often in the recurrence group. Although not reaching statistical significance, a trend towards higher rates of cerebrovascular events in the recurrence group was observed [11 (11\%) vs. 4 $(6.5 \%), p=0.34]$. There was no difference with regard to the presence of coronary artery disease (CAD) [33 (33\%) vs. 15 (24.2\%), $p=0.24$ ] between the two groups. Impaired renal function was found more frequently in patients with $\mathrm{AF}$ recurrence, reflected in i) higher creatinine levels $(1.3 \pm 0.6$ $\mathrm{mg} / \mathrm{dl}$ vs. $1.0 \pm 0.2 \mathrm{mg} / \mathrm{dl}, p=0.02)$, ii) reduced glomerular filtration rate (GFR) $\left(62.0 \pm 19.1 \mathrm{ml} / \mathrm{min} / 1.73 \mathrm{~m}^{2} v s .72 .3 \pm 17.4\right.$ $\left.\mathrm{ml} / \mathrm{min} / 1.73 \mathrm{~m}^{2}, p<0.001\right)$ and iii) stage of chronic kidney disease $\geq$ III [37 (37\%) vs. 12 (19.4\%), $p=0.02$ ]

Anticoagulation strategies showed no difference between the two groups, while a considerable number of patients in the recurrence group were on digitalis [14 (14\%) vs. 1 $(1.6 \%), p<0.01]$.

Clinical features and atrial fibrillation characteristics. Permanent AF was more frequent in the recurrence group [45 (45\%) vs. 17 (27.4\%), $p=0.03$ ] compared to the nonrecurrence group. In addition, patients in the recurrence group had a distinct risk profile, displayed in higher $\mathrm{CHA}_{2} \mathrm{DS}_{2} \mathrm{VASc}$ $(3.3 \pm 1.6 v s .2 .5 \pm 1.6, p<0.01)$ and HASBLED score $(2.3 \pm 1.0$ vs. $1.7 \pm 1.1, p<0.001)$. The averaged European Heart Rhythm Association (EHRA) score was higher in the recurrence group (2.4 $\pm 0.9 v s .2 .1 \pm 0.8, p=0.02)$ compared to the non-recurrence group, similar to the number of highly symptomatic patients (EHRA $\geq$ III) $[57(57 \%)$ vs. $18(29.0 \%), p<0.001]$. Patients in the recurrence group had more often a prior treatment attempting to control the heart rhythm (CV 56\% vs. $29.0 \%$, $p<0.001$; PVI $31 \%$ vs. $12.9 \%, p<0.01)$ and a positive history of atrial flutter [35 (35\%) vs. 12 (19.4\%), $p=0.03$ ]. Table II gives an overview of the AF characteristics.

Echocardiographic characteristics recurrence vs. nonrecurrence. Left ventricular function (LVEF in \%) was significantly lower in the recurrence group $v s$. the nonrecurrence group $(53.1 \pm 11.6 v s .59 .3 \pm 6.4, p<0.001)$, while a lower right ventricular function was also measured in the tricuspid annular plane systolic excursion (TAPSE) (mm) $(19.2 \pm 4.2$ vs. $21.9 \pm 3.6, p<0.001)$ in the recurrence group. Additionally, the left ventricular end-diastolic diameter (LVEDD) was higher in the recurrence group (49.4 $\pm 6.4 \mathrm{vs}$. $46.5 \pm 4.9, p=0.03)$. Enlargement of the LA was more common in the recurrence group, measured as the LA diameter in parasternal M-mode $(\mathrm{mm})(43.4 \pm 7.2 \mathrm{vs}$. $38.8 \pm 7.0, p<0.01)$ and LAVI $\left(\mathrm{ml} / \mathrm{m}^{2}\right) \quad(49.0 \pm 18.6 v s$. $26.3 \pm 7.0, p<0.0001)$. Consequently, to assess the diastolic function maximum tricuspid regurgitation velocity (TR Vmax) and average E/e' were evaluated, with higher values
Table III. Echocardiographic characteristics recurrence vs. nonrecurrence. Data are presented as mean $\pm S D$ or $n(\%)$ of subjects. Diastolic dysfunction is defined as the presence of $\geq 2$ characteristics (E/e' $>14$, septal $e^{\prime}<7 \mathrm{~cm} / \mathrm{s}$ or lateral $e^{\prime}<10 \mathrm{~cm} / \mathrm{s}, T R$ Vmax $>2.8 \mathrm{~m} / \mathrm{s}$, $\left.L A V I>34 \mathrm{ml} / \mathrm{m}^{2}\right)$.

\begin{tabular}{lccc}
\hline & $\begin{array}{c}\text { Non- } \\
\text { recurrence } \\
(\mathrm{n}=62)\end{array}$ & $\begin{array}{c}\text { Recurrence } \\
(\mathrm{n}=100)\end{array}$ & $p$-Value \\
& $59.3 \pm 6.4$ & $53.1 \pm 11.6$ & $<0.001$ \\
\hline LVEF (\%) & $13(21.0)$ & $37(37.0)$ & 0.41 \\
Myocardial hypertrophy, & & \\
n (\%) & $46.5 \pm 4.9$ & $49.4 \pm 6.4$ & 0.03 \\
LVEDD (mm) & $38.8 \pm 7.0$ & $43.4 \pm 7.2$ & $<0.01$ \\
LA, M-Mode (mm) & $55.2 \pm 14.3$ & $88.3 \pm 26.3$ & $<0.0001$ \\
LA Volume, 2Ch (ml) & $52.5 \pm 19.8$ & $87.4 \pm 27.2$ & 0.0002 \\
LA Volume, 4Ch (ml) & $26.3 \pm 7.0$ & $49.0 \pm 18.6$ & $<0.0001$ \\
LAVI (ml/m $\left.{ }^{2}\right)$ & $16.9 \pm 4.5$ & $18.7 \pm 4.8$ & $<0.0001$ \\
RA-Area (cm $\left.{ }^{2}\right)$ & $21.9 \pm 3.6$ & $19.2 \pm 4.2$ & $<0.001$ \\
TAPSE (mm) & $9.8 \pm 5.0$ & $12.5 \pm 5.8$ & 0.04 \\
E/E' & $2.3 \pm 0.4$ & $2.7 \pm 0.5$ & $<0.01$ \\
TR Vmax (m/s) & $9(14.5)$ & $46(45.5)$ & 0.0001 \\
Diastolic dysfunction, n $(\%)$ & & \\
\hline
\end{tabular}

2Ch: Two chamber view; 4Ch: four chamber view; LVEF: left ventricular ejection fraction; LVEDD: left ventricular end diastolic diameter; LA: left atrium; LAVI: left atrial volume index; TAPSE: tricuspid annular plane systolic excursion; RA: right atrium; TR V: tricuspid regurgitation velocity.

emerging for the recurrence group: i) TR $\operatorname{Vmax}(\mathrm{m} / \mathrm{s})$ $(2.7 \pm 0.5 v s .2 .3 \pm 0.4, p<0.01)$, and ii) $\mathrm{E} / \mathrm{e}^{\prime}(12.5 \pm 5.8 v s$. $9.8 \pm 5.0, p=0.04)$. The RA area, assessed in an apical $4 \mathrm{Ch}$ view, was, likewise, enlarged in the recurrence group $(18.7 \pm 4.8 v s .16 .9 \pm 4.5, p<0.0001)$. Table III gives an overview of the echocardiographic characteristics.

ROC analyses for LAVI and LA diameter. Receiver operating characteristic (ROC) curves were used for the entire group of patients to find the optimal cut-off values for LAVI and LA diameter (measured by M-Mode), maximizing the sum of sensitivity and specificity with help of the Youden-Index, identifying measurements that correspond most with the risk for AF recurrence. The following values could be detected as threshold:

LAVI $>36 \mathrm{ml} / \mathrm{m}^{2}(p<0.0001, \mathrm{AUC}=0.92,95 \% \mathrm{CI}=0.8-0.97$, sensitivity $=76 \%$, specificity $=94 \%$ ) and LA diameter $>41 \mathrm{~mm}$ ( $p=0.0019$, AUC $0.69,95 \%$ CI 0.57 to 0.81 , sensitivity $66 \%$, specificity $66 \%$ ). LAVI showed way more significance and stronger correlation with AF recurrences compared to LA diameter. The comparison of the two ROC curves can be found in Figure 2.

Multivariate analysis. Based on the results of the univariate analysis, we tried to establish a risk model, displaying the relationship between LA enlargement, diastolic dysfunction 
A

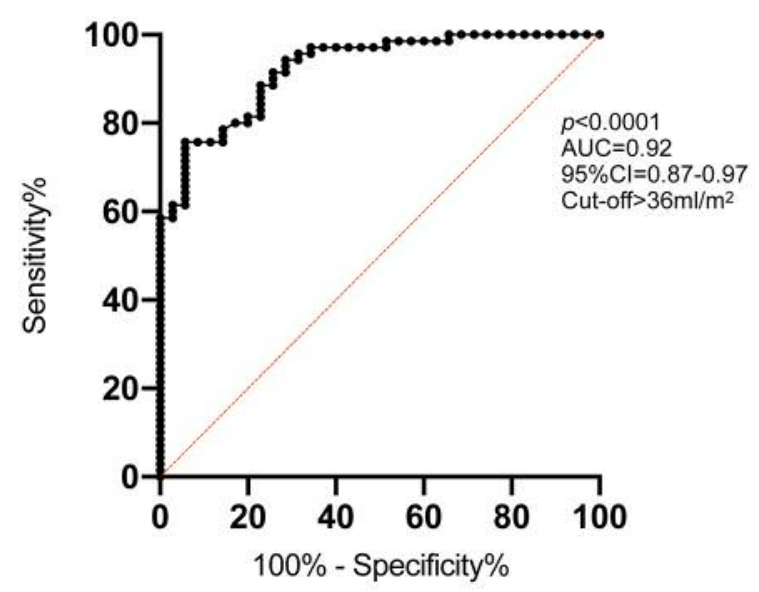

B

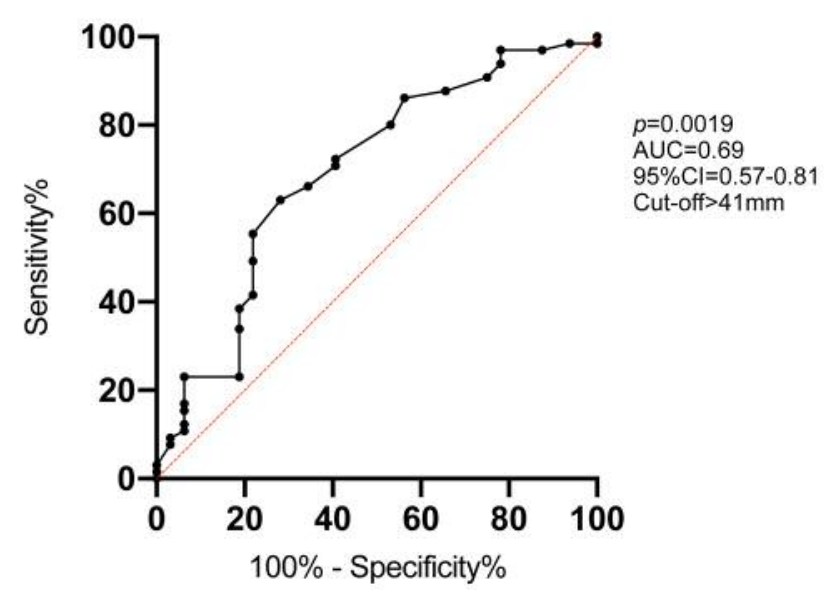

Figure 2. Comparison of ROC curves for AF recurrence in dependence of $A) L A V I\left(\mathrm{ml} / \mathrm{m}^{2}\right)$ and B) LA diameter measured by $M-M o d e(m m)$. AF: Atrial fibrillation; AUC: area under the curve; CI: confidence interval; LA: left atrial; LAVI: left atrial volume index; ROC: receiver operating characteristics.

and heart failure. Both diastolic dysfunction $(\mathrm{HR}=1.6$, $95 \% \mathrm{CI}=1.3=2.1, p=0.04$ ) and LA enlargement (defined as LAVI $>36 \mathrm{ml} / \mathrm{m}^{2}$, whereby the cut-off was determined by ROC-analysis, with $\mathrm{HR}=2.1,95 \% \mathrm{CI}=1.8-2.7, p<0.0001$ ) could be identified as independent predictors for $\mathrm{AF}$ recurrence, in contrast to heart failure, for which no statistical significance could be detected. The reciprocal relationship between $\mathrm{AF}$ and diastolic dysfunction is displayed in Figure 3.

\section{Discussion}

Despite advances in rhythm control strategies in patients with $\mathrm{AF}$, recurrence of AF still remains a major issue. Therefore, we tried to ascertain predictors of recurrence by analyzing clinical and echocardiographical parameters. The main findings of the present study are: i) Recurrence of $\mathrm{AF}$ occurred frequently in our study cohort $(62 \%)$, ii) both left and right ventricular function were decreased in the recurrence group, iii) diastolic dysfunction and enlargement of the left atrium were more common in patients with recurrent $\mathrm{AF}$ and could be identified as independent predictors.

Enlargement of the left atrium is a common finding in patients with AF with an impact on the success of their rhythm control therapy. In our cohort, echocardiographical assessment of the LA showed significantly higher values for LA diameter measured by M-Mode and LAVI in AF recurrence. LA diameter $>41 \mathrm{~mm}$ and LAVI $>36 \mathrm{ml} / \mathrm{m}^{2}$ were detected as cut-off values. These findings are in line with current analyses showing that left atrial enlargement is

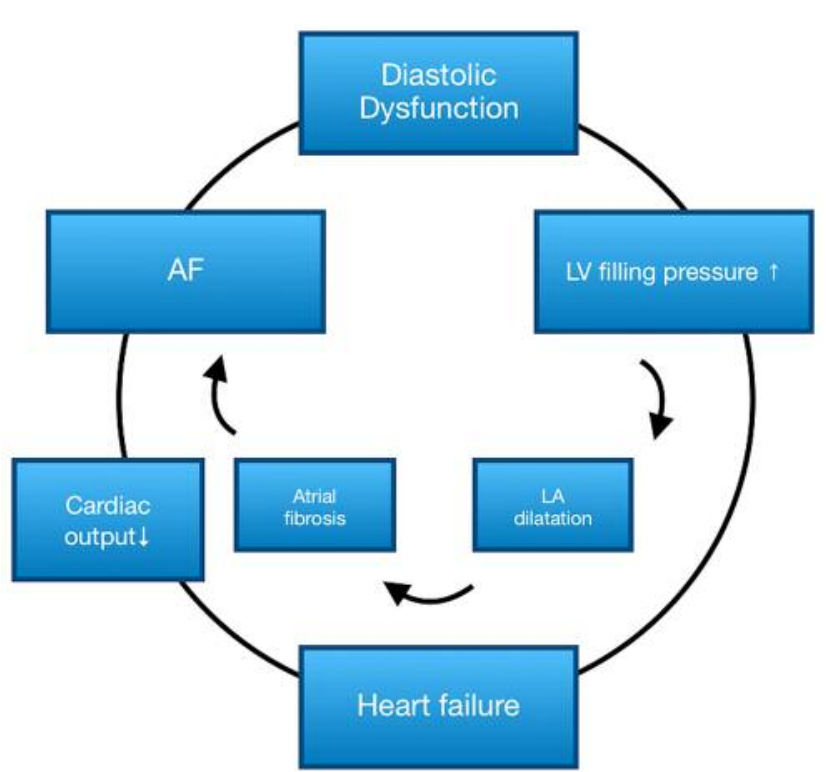

Figure 3. Vicious circle of $A F$ and heart failure. AF: Atrial fibrillation; LA: left atrium; LV: left ventricle.

a negative predictor of successful restoration of the sinus rhythm following rhythm control attempt (23, 24). Concordant to our observations, Akdemir et al., have detected the same cut-off value for LAVI in patients following CV (23), while other investigations have stated lower values for LAVI as significant (25-27). The different cut-off values for LAVI can be due to different sample sizes 
and different patient characteristics. Besides the recurrence of AF, LAVI predicts mortality risk independent of LV geometry in patients with HFpEF (28). Remarkably, in our analyzed patient cohort, LAVI predicted AF recurrence much more accurately compared to the LA diameter, indicating that LAVI is a more accurate approach for determining the LA size and predicting AF recurrences, as previously described (26).

Kornej et al., have found comparable values for potential predictors for AF recurrence, such as LA diameter (>43 mm), impaired GFR $\left(<60 \mathrm{ml} / \mathrm{min} / 1.73 \mathrm{~m}^{2}\right)$, permanent AF, heart failure $(\mathrm{EF}<50 \%)$ and age $>65$ years, which they integrated in a risk score (28). Except for age, these observations are congruent with ours.

Assessing diastolic function has revealed significantly impaired diastolic function in the recurrence group, giving another pathophysiological hint for LA enlargement and AF recurrence (29).

In line with previous results (29), LVEDD was higher in the recurrence group compared to the non-recurrence one, which reflects diastolic dysfunction and impaired LVEF, both observed in AF recurrence. Averaged decreased TAPSE as well as impaired right ventricular function could be found more commonly in the recurrence group. To our knowledge, this is the first time a study shows that impaired right ventricular function is associated with $\mathrm{AF}$ recurrence in the overall population. In addition to LA enlargement, RA dilatation was significantly increased in patients with AF recurrence. These results are in line with a cohort of AF patients with hypertrophic cardiomyopathy, where TAPSE and RA dilatation were altered (30). Recently, it was shown that impaired RV function predicts cardiovascular death in the general population, indicating that this may have the potential to shed further light on the pathophysiological background of RV function (31).

While sex didn't show any significant difference in this patient cohort, it has been reported that female sex is a risk factor for AF recurrences (32). Increased BMI, diabetes, history of cerebrovascular events and coronary artery disease show conflicting data in the literature, thus a single component effect can't be specified, but in combination with other risk factors and integrated in scores, a relevant effect can be yielded (32-34). Hypertension and heart failure, including an often detected HFpEF compared to HFrEF in the recurrence group, in combination with an increased NYHA score, are general risk factors for $\mathrm{AF}$ recurrence $(32,33,35)$. As AF and heart failure frequently coexist, which one is preceding and which is following is sometimes as hard to answer as the "chicken or the egg" question. As displayed in our results, heart failure, diastolic dysfunction and AF form a vicious circle, promoting LA enlargement via increased diastolic pressure, thus leading to atrial remodeling, which begets $\mathrm{AF}$ (36). Impaired renal function, as shown in this analysis, is also a risk factor for $\mathrm{AF}$ recurrence, reflecting the role of the cardio-renal system, as it gets influenced by cardiac remodeling, metabolic abnormalities and oxidative stress (34, $36,37)$. There was no difference in our study with respect to concomitant medication, except for digitalis. The increased use of digitalis in the recurrence group is most likely due to the higher AF symptom burden, reflected in higher EHRA scores, without an improvement from the use of beta-blockers.

The duration of AF is significantly linked to the recurrence of AF, most likely due to level of atrial remodeling and fibrosis, which indicates paroxysmal AF as a positive predictor for restoring the sinus rhythm $(32,36)$. An increased $\mathrm{CHA}_{2} \mathrm{DS}_{2}$-VASc-Score, which characterizes cardiovascular risk factors, is not just a score for thromboembolic risk but it also predicts mortality in cardiac patients and as well AF recurrence $(34,38)$. Patients with a higher $\mathrm{CHA}_{2} \mathrm{DS}_{2}$-VASc score are, therefore, not only at stake for thromboembolic events but also for AF itself (39, 40). Patients in the recurrence group showed a distinct risk profile reflected in higher $\mathrm{CHA}_{2} \mathrm{DS}_{2}$-VASc and HASBLED scores, as well as larger number of AF-relevant symptoms (EHRA $\geq$ III). Controversially, a study comparing patients with symptomatic and asymptomatic AF, has revealed more progression of $\mathrm{AF}$ and worse prognosis in asymptomatic patients (41). Most likely, rhythm control attempt with $\mathrm{CV}$ or AF ablation is administered to symptomatic patients, thus a selection bias in the analyzed patient cohort is possible.

In conclusion, recurrence of AF emerges frequently following initial rhythm control attempt. Given that the prevalence of AF is continuously increasing, there is an imperative need for better risk stratification of candidates for rhythm control therapy. Patients who developed AF recurrences had both decreased left and right ventricular function. Diastolic dysfunction and enlargement of the left atrium were more common in patients with recurrent $\mathrm{AF}$ and could be identified as independent predictors. These findings corroborate the benefit of a rhythm control strategy, as AF is a chronic progressive condition leading to a vicious circle of diastolic dysfunction and heart failure, which needs to be broken. The prediction of AF recurrence by a single value doesn't seem to be a promising approach, in contrast to risk scores integrating LAVI and diastolic dysfunction, which need to be tested and implemented in clinical praxis.

\section{Registration}

The study is registered in the German Clinical Trials Register: https://www.drks.de/drks_web/navigate.do?navigationId=trial.HTM L\&TRIAL_ID=DRKS00019007.

\section{Conflicts of Interest}

None. 


\section{Authors' Contributions}

Data were collected by TS and MK. MK analyzed all data and made a decisive contribution to completion of the manuscript. Echocardiographic assessment was performed by CD. VK and IA performed either pulmonary vein isolation or cardioversion. TP and $\mathrm{MB}$ provided critical revisions for intellectual content. $\mathrm{AH}$ conceived the study, approved the statistical analysis and prepared the final manuscript draft. All Authors approved the final version.

\section{References}

1 Benjamin EJ, Wolf PA, D’Agostino RB, Silbershatz H, Kannel WB and Levy D: Impact of atrial fibrillation on the risk of death: The framingham heart study. Circulation 98(10): 946-952, 1998. PMID: 9737513. DOI: 10.1161/01.cir.98.10.946

2 Heijman J, Voigt N, Nattel S and Dobrev D: Cellular and molecular electrophysiology of atrial fibrillation initiation, maintenance, and progression. Circ Res 114(9): 1483-1499, 2014. PMID: 24763466. DOI: 10.1161/CIRCRESAHA. 114.302226

3 Thrall G, Lane D, Carroll D and Lip GY: Quality of life in patients with atrial fibrillation: A systematic review. Am J Med 119(5): 448.e441-448. e419, 2006. PMID: 16651058. DOI: 10.1016/j.amjmed.2005.10.057

4 Nattel S, Burstein B and Dobrev D: Atrial remodeling and atrial fibrillation: Mechanisms and implications. Circ Arrhyth Electrophysiol 1(1): 62-73, 2008. PMID: 19808395. DOI: 10.1161/CIRCEP.107.754564

5 Wang TJ, Larson MG, Levy D, Vasan RS, Leip EP, Wolf PA, D'Agostino RB, Murabito JM, Kannel WB and Benjamin EJ: Temporal relations of atrial fibrillation and congestive heart failure and their joint influence on mortality: The framingham heart study. Circulation 107(23): 2920-2925, 2003. PMID: 12771006. DOI: 10.1161/01.CIR.0000072767.89944.6E

6 Rosenberg MA and Manning WJ: Diastolic dysfunction and risk of atrial fibrillation: A mechanistic appraisal. Circulation 126(19): 2353-2362, 2012. PMID: 23129702. DOI: 10.1161/CIRCULATIONAHA.112.113233

7 Marrouche NF, Brachmann J, Andresen D, Siebels J, Boersma L, Jordaens L, Merkely B, Pokushalov E, Sanders P and Proff J: Catheter ablation for atrial fibrillation with heart failure. $\mathrm{N}$ Engl J Med 378(5): 417-427, 2018. PMID: 29385358. DOI: 10.1056/NEJMoa1707855

8 Berruezo A, Tamborero D, Mont L, Benito B, Tolosana JM, Sitges M, Vidal B, Arriagada G, Méndez F and Matiello M: Preprocedural predictors of atrial fibrillation recurrence after circumferential pulmonary vein ablation. Eur Heart J 28(7): 836841, 2007. PMID: 17395676. DOI: 10.1093/eurheartj/ehm027

9 Burstein B and Nattel S: Atrial fibrosis: Mechanisms and clinical relevance in atrial fibrillation. J Am Coll Cardiol 51(8): 802-809, 2008. PMID: 18294563. DOI: 10.1016/j.jacc.2007.09.064

10 Marrouche NF, Wilber D, Hindricks G, Jais P, Akoum N, Marchlinski F, Kholmovski E, Burgon N, Hu N and Mont L: Association of atrial tissue fibrosis identified by delayed enhancement mri and atrial fibrillation catheter ablation: The decaaf study. JAMA 311(5): 498-506, 2014. PMID: 24496537. DOI: $10.1001 /$ jama.2014.3
11 De Vos CB, Pisters R, Nieuwlaat R, Prins MH, Tieleman RG, Coelen R-JS, van den Heijkant AC, Allessie MA and Crijns HJ: Progression from paroxysmal to persistent atrial fibrillation: Clinical correlates and prognosis. J Am Coll Cardiol 55(8): 725731, 2010. PMID: 20170808. DOI: 10.1016/j.jacc.2009.11.040

12 Kirchhof P, Benussi S, Kotecha D, Ahlsson A, Atar D, Casadei B, Castella M, Diener H-C, Heidbuchel H and Hendriks J: 2016 esc guidelines for the management of atrial fibrillation developed in collaboration with eacts. Eur Heart J 37(38): 28932962, 2016. PMID: 27567408. DOI: 10.1093/eurheartj/ehw210

13 Association WM: World medical association declaration of helsinki. Ethical principles for medical research involving human subjects. Bull World Health Organ 79(4): 373, 2001. PMID: 24141714. DOI: 10.1001/jama.2013.281053

14 Gottdiener JS, Bednarz J, Devereux R, Gardin J, Klein A, Manning WJ, Morehead A, Kitzman D, Oh JK and Quinones M: American society of echocardiography recommendations for use of echocardiography in clinical trials: A report from the american society of echocardiography's guidelines and standards committee and the task force on echocardiography in clinical trials. J Am Soc Echocardiogr 17(10): 1086-1119, 2004. PMID: 15452478. DOI: 10.1016/j.echo.2004.07.013

15 Abhayaratna WP, Seward JB, Appleton CP, Douglas PS, Oh JK, Tajik AJ and Tsang TS: Left atrial size: Physiologic determinants and clinical applications. J Am Coll Cardiol 47(12): 2357-2363, 2006. PMID: 16781359. DOI: 10.1016/j.jacc.2006.02.048

16 Ujino K, Barnes ME, Cha SS, Langins AP, Bailey KR, Seward JB and Tsang TS: Two-dimensional echocardiographic methods for assessment of left atrial volume. Am J Cardiol 98(9): 11851188, 2006. PMID: 17056324. DOI: 10.1016/j.amjcard. 2006.05.040

17 Lang RM, Badano LP, Mor-Avi V, Afilalo J, Armstrong A, Ernande L, Flachskampf FA, Foster E, Goldstein SA, Kuznetsova T, Lancellotti P, Muraru D, Picard MH, Rietzschel ER, Rudski L, Spencer KT, Tsang W and Voigt JU: Recommendations for cardiac chamber quantification by echocardiography in adults: An update from the american society of echocardiography and the european association of cardiovascular imaging. J Am Soc Echocardiogr 28(1): 1-39.e14, 2015. PMID: 25559473. DOI: 10.1016/j.echo.2014.10.003

18 Oh JK, Park S-J and Nagueh SF: Established and novel clinical applications of diastolic function assessment by echocardiography. Circ Cardiovasc Imaging 4(4): 444-455, 2011. PMID: 21772012. DOI: 10.1161/CIRCIMAGING.110.961623

19 Chapman CB, Ewer SM, Kelly AF, Jacobson KM, Leal MA and Rahko PS: Classification of left ventricular diastolic function using american society of echocardiography guidelines: Agreement among echocardiographers. Echocardiography 30(9): 1022-1031, 2013. PMID: 23551740. DOI: 10.1111/echo.12185

$20 \mathrm{Ho}$ CY and Solomon SD: A clinician's guide to tissue doppler imaging. Circulation 113(10): e396-e398, 2006. PMID: 16534017. DOI: 10.1161/CIRCULATIONAHA.105.579268

21 Okura H, Takada Y, Kubo T, Iwata K, Mizoguchi S, Taguchi H, Toda I, Yoshikawa J and Yoshida K: Tissue doppler-derived index of left ventricular filling pressure, e/e', predicts survival of patients with non-valvular atrial fibrillation. Heart 92(9): 1248-1252, 2006. PMID: 16449507. DOI: 10.1136/hrt. 2005.082594

22 Nagueh SF, Smiseth OA, Appleton CP, Byrd BF, Dokainish H, Edvardsen T, Flachskampf FA, Gillebert TC, Klein AL and 
Lancellotti P: Recommendations for the evaluation of left ventricular diastolic function by echocardiography: An update from the american society of echocardiography and the european association of cardiovascular imaging. Eur J Echocardiogr 17(12): 1321-1360, 2016. PMID: 27422899. DOI: 10.1093/ehjci/jew082

23 Njoku A, Kannabhiran M, Arora R, Reddy P, Gopinathannair R, Lakkireddy D and Dominic P: Left atrial volume predicts atrial fibrillation recurrence after radiofrequency ablation: A metaanalysis. Europace 20(1): 33-42, 2018. PMID: 28444307. DOI: 10.1093/europace/eux013

24 Zhuang J, Wang Y, Tang K, Li X, Peng W, Liang C and Xu Y: Association between left atrial size and atrial fibrillation recurrence after single circumferential pulmonary vein isolation: A systematic review and meta-analysis of observational studies. Europace 14(5): 638-645, 2012. PMID: 22117033. DOI: 10.1093/europace/eur364

25 Akdemir B, Altekin RE, Kucuk M, Yanikoglu A, Karakas MS, Aktas A, Demir I and Ermis C: The significance of the left atrial volume index in cardioversion success and its relationship with recurrence in patients with non-valvular atrial fibrillation subjected to electrical cardioversion: A study on diagnostic accuracy. Anadolu Kardiyol Derg 13(1): 18-25, 2013. PMID: 23070632. DOI: 10.5152/akd.2013.003

26 Marchese P, Malavasi V, Rossi L, Nikolskaya N, Donne GD, Becirovic M, Colantoni A, Luciani A and Modena MG: Indexed left atrial volume is superior to left atrial diameter in predicting nonvalvular atrial fibrillation recurrence after successful cardioversion: A prospective study. Echocardiography 29(3): 276-284, 2012. PMID: 22098539. DOI: 10.1111/j.1540-8175. 2011.01580.x

27 Shin SH, Park MY, Oh WJ, Hong SJ, Pak HN, Song WH, Lim DS, Kim YH and Shim WJ: Left atrial volume is a predictor of atrial fibrillation recurrence after catheter ablation. J Am Soc Echocardiogr 21(6): 697-702, 2008. PMID: 18187293. DOI: 10.1016/j.echo.2007.10.022

28 Kornej J, Hindricks G, Shoemaker MB, Husser D, Arya A, Sommer P, Rolf S, Saavedra P, Kanagasundram A and Whalen SP: The apple score: A novel and simple score for the prediction of rhythm outcomes after catheter ablation of atrial fibrillation. Clin Res Cardiol 104(10): 871-876, 2015. PMID: 25876528. DOI: $10.1007 / \mathrm{s} 00392-015-0856-\mathrm{x}$

29 Lizewska-Springer A, Dabrowska-Kugacka A, Lewicka E, Drelich L, Krolak $\mathrm{T}$ and Raczak G: Echocardiographic predictors of atrial fibrillation recurrence after catheter ablation: A literature review. Cardiol J, 2018. PMID: 29924375. DOI: 10.5603/CJ.a2018.0067

30 Doesch C, Lossnitzer D, Rudic B, Tueluemen E, Budjan J, Haubenreisser H, Henzler T, Schoenberg SO, Borggrefe M and Papavassiliu T: Right ventricular and right atrial involvement can predict atrial fibrillation in patients with hypertrophic cardiomyopathy? Int J Med Sci 13(1): 1-7, 2016. PMID: 26812947. DOI: $10.7150 / \mathrm{ijms} .13530$

31 Modin D, Mogelvang R, Andersen DM and Biering-Sorensen T: Right ventricular function evaluated by tricuspid annular plane systolic excursion predicts cardiovascular death in the general population. J Am Heart Assoc 8(10): e012197, 2019. PMID: 31088196. DOI: 10.1161/JAHA.119.012197

32 Sultan A, Luker J, Andresen D, Kuck KH, Hoffmann E, Brachmann J, Hochadel M, Willems S, Eckardt L, Lewalter T, Senges $\mathrm{J}$ and Steven D: Predictors of atrial fibrillation recurrence after catheter ablation: Data from the german ablation registry. Sci Rep 7(1): 16678, 2017. PMID: 29192223. DOI: 10.1038/ s41598-017-16938-6

33 Holmqvist F, Simon D, Steinberg BA, Hong SJ, Kowey PR, Reiffel JA, Naccarelli GV, Chang P, Gersh BJ, Peterson ED, Piccini JP and Investigators O-A: Catheter ablation of atrial fibrillation in u.S. Community practice--results from outcomes registry for better informed treatment of atrial fibrillation (orbitaf). J Am Heart Assoc 4(5), 2015. PMID: 25999401. DOI: 10.1161/JAHA.115.001901

34 Kosich F, Schumacher K, Potpara T, Lip GY, Hindricks G and Kornej J: Clinical scores used for the prediction of negative events in patients undergoing catheter ablation for atrial fibrillation. Clin Cardiol 42(2): 320-329, 2019. PMID: 30578568. DOI: $10.1002 / \mathrm{clc} .23139$

35 Ganesan AN, Shipp NJ, Brooks AG, Kuklik P, Lau DH, Lim HS, Sullivan T, Roberts-Thomson KC and Sanders P: Long-term outcomes of catheter ablation of atrial fibrillation: A systematic review and meta-analysis. J Am Heart Assoc 2(2): e004549, 2013. PMID: 23537812. DOI: 10.1161/JAHA.112.004549

36 Lip GY, Fauchier L, Freedman SB, Van Gelder I, Natale A, Gianni C, Nattel S, Potpara T, Rienstra M, Tse HF and Lane DA: Atrial fibrillation. Nat Rev Dis Primers 2: 16016, 2016. PMID: 27159789. DOI: $10.1038 /$ nrdp.2016.16

$37 \mathrm{Li} \mathrm{M}$, Liu T, Luo D and Li G: Systematic review and metaanalysis of chronic kidney disease as predictor of atrial fibrillation recurrence following catheter ablation. Cardiol $\mathrm{J}$ 21(1): 89-95, 2014. PMID: 23990188. DOI: 10.5603/CJ. a2013.0116

38 Saliba W, Gronich N, Barnett-Griness $\mathrm{O}$ and Rennert G: Usefulness of CHADS2 and CHA2DS2-VASc scores in the prediction of new-onset atrial fibrillation: A population based study. Am J Med 129(8): 843-849, 2016. PMID: 27012854. DOI: $10.1016 /$ j.amjmed.2016.02.029

39 Zuo M-L, Liu S, Chan K-H, Lau K-K, Chong B-H, Lam K-F, Chan Y-H, Lau Y-F, Lip GY and Lau C-P: The chads 2 and cha 2 ds 2 -vasc scores predict new occurrence of atrial fibrillation and ischemic stroke. J Interv Card Electrophysiol 37(1): 47-54, 2013. PMID: 23389054. DOI: 10.1007/s10840-012-9776-0

40 Letsas KP, Efremidis M, Giannopoulos G, Deftereos S, Lioni L, Korantzopoulos P, Vlachos K, Xydonas S, Kossyvakis C and Sideris A: Chads2 and cha2ds2-vasc scores as predictors of left atrial ablation outcomes for paroxysmal atrial fibrillation. Europace 16(2): 202-207, 2013. PMID: 23813452. DOI: 10.1093/ europace/eut 210

41 Potpara TS, Polovina MM, Marinkovic JM and Lip GY: A comparison of clinical characteristics and long-term prognosis in asymptomatic and symptomatic patients with first-diagnosed atrial fibrillation: The belgrade atrial fibrillation study. Int $\mathbf{J}$ Cardiol 168(5): 4744-4749, 2013. PMID: 23958417. DOI: 10.1016/j.ijcard.2013.07.234 